\title{
Toxicity of glucocorticosteroids in autoimmune blistering diseases
}

\section{Otoimmün büllöz hastalıklarda glukokortikosteroid toksisitesi}

\author{
Asli Bilgic ${ }^{1}$, Dedee F Murrell ${ }^{2,3}$ \\ ${ }^{1}$ Dermatology Clinic, University of Health Sciences, Antalya Training and Research Hospital, Antalya, Turkey, ${ }^{2}$ Dept. of Dermatology, St George \\ Hospital, Sydney, Australia, ${ }^{3}$ Faculty of Medicine, University of New South Wales, Sydney, Australia
}

\begin{abstract}
Glucocorticosteroids (GCs), have been the mainstay treatment for several dermatological diseases such as autoimmune bullous diseases (AIBDs). However, they come with a great cost of GCs-associated adverse events causing mortality and morbidity. Recently, a new measure to evaluate toxicity due to GCs' use has been demonstrated to be reliable.
\end{abstract}

This review aimed to summarise toxicity attributed to GCs use and give more insight about this new toxicity index.

Key words: glucocorticoid, adverse events, toxicity, dermatology, autoimmune blistering diseases

\section{O̊zet}

Glukokortikoidler, otoimmün büllöz hastalıklar başta olmak üzere çeşitli dermatolojik hastalıkların temel tedavisi olmuştur. Bununla birlikte, pek çok morbidite ve mortaliteye neden olan yan etkileri vardır. Son zamanlarda, glukokortikoidlerin kullanımına bağlı toksisiteyi değerlendirmek için yeni bir ölçüm sistemi geliştirilmiş ve güvenilir olduğu gösterilmiştir.

Bu derleme, glukokortikoidlerin kullanımına bağlı oluşan yan etkileri özetlemeyi ve bu yeni tanıtılan toksisite indeksi hakkında daha fazla bilgi vermeyi amaçlamaktadır.

Anahtar kelimeler: glukokortikosteroid, yan etkiler, toksisite, dermatoloji, otoimmün büllöz hastalklar

\section{Introduction}

Glucocorticosteroids (GCs), which were introduced half a century ago, have been the cornerstone of treatment for many diseases including dermatological diseases. Although the use of GCs has been invaluable for some diseases (such as pemphigus, rheumatologic diseases, etc.), they come with a great cost of GCs-associated adverse events, resulting in residual morbidity and mortality. It is generally accepted that the risk of GCs toxicity depends on both GCs dosage and duration as well as the patients' individual risk factors. ${ }^{1}$

In the past few decades, there have been great improvements in terms of health care and treatment for patients with

Corresponding author: Dedee F. Murrell, Dept. of Dermatology, St George Hospital, UNSW, Kogarah, 2217, NSW Sydney, Australia, Phone: +61 29113 2543, E-mail: d.murrell@unsw.edu.au

Received: 27 August 2019 Accepted: 25 September 2019

Conflicts of Interest: DFM is an investigator and advisory board member for Principia-biopharma and was an investigator and advisor for Roche, GSK/Novartis, and Lilly. She is a co-creator of the GTI index but holds no royalties for this.

Funding: None

This work is licensed under a Creative Commons Attribution-NonCommercial 4.0 International License. 
autoimmune blistering diseases (AIBD) using GCs. Systemic corticosteroids ( $0.5 \mathrm{mg}$ to $1.5 \mathrm{mg} / \mathrm{kg} /$ day), alone or in combination with immunosuppressive agents remain the main treatment option in most places for now ${ }^{2}$; however, rituximab has recently been shown to be more effective and safer for inducing complete remission than the former approach, receiving FDA approval for the initial treatment of moderate to severe pemphigus ${ }^{3}$ and international consensus recommendation as first line treatment. $^{4}$

Although the mortality rate within one year has decreased from $75-80 \%$ of patients with pemphigus to $5-10 \%$ with the discovery of GCs, nowadays the main morbidity and mortality seem to be as a result of GCs treatment. In addition to rituximab, several novel therapeutic options are currently being studied for AIBD. Future treatments will focus more on specifically targeted molecular therapies which might have less systemic immunosuppression and less side effects. ${ }^{5}$

This review aimed to provide information about the use of GCs in dermatology especially for AIBD and toxicity attributed to their usage.

\section{Glucocorticoids}

GCs are drugs that mimic cortisol, a 'flight and fight' hormone secreted from the adrenal glands. Different types of GCs (cortisone, prednisone, prednisolone, methylprednisolone, dexamethasone, triamcinolone, etc.) have been developed. ${ }^{6}$ Synthetic GCs have less mineralocorticoid effects but more GC effects. There are several diseases indicated for the use of GCs, the most common are skin and musculoskeletal conditions. Others include allergic, immunological diseases, eye, respiratory system, gastrointestinal system (GIS) diseases, some infectious diseases, various malignancies and neurological diseases. ${ }^{6,7}$

GCs were first used systemically for a rheumatoid arthritis patient in 1948 and then used for dermatological conditions beginning in 1951. After that, topical use of GCs was also demonstrated for eczema. ${ }^{8,9}$ Steroids can be used topically, systemically (oral, IV, IM) and intralesionally for dermatological diseases.

\section{Topical application}

Topical steroids potency is rated differently across the Atlantic. In North America, topical GCs are divided into seven power classes (Stoughton- Cornell classification) with the most potent being class I, according to their vasoconstrictive effects and have several different formulations with anti-inflammatory, antiproliferative, immunosuppressive and vasoconstrictive effects. ${ }^{10,11}$ In the United Kingdom and Australia, for example, GCs are divided into 4 classes, with class 4 being the most potent. ${ }^{12,13}$

Superpotent GCs, such as clobetasol propionate, are preferable especially for AIBD [specifically for bullous pemphigoid (BP), pemphigus foliaceus (PF) and pemphigus erythematosus (PE)] as they reduce the need for systemic GCs although their topical application has side effects such as skin atrophy, purpura, telangiectasias, acneiform or rosaceous rashes, facial plethora, skin infections, striae, etc. ${ }^{14,15}$

For BP, clobetasol propionate $0.05 \%$ cream (or ointment) applied twice daily 30-40 g per day, is the mainstay initial treatment. It is used over the entire body starting first with blisters and erosions and then continuing to normal skin except the face. ${ }^{16}$ After the initial treatment, the application should be reduced to daily treatment in the first month, followed by treatment every 2 days in the second month, then twice per week in the third month and finally once per week starting in the fourth month before ceasing it totally. ${ }^{16}$ In more severe involvement of BP and PF, systemic corticosteroids ( 0.5 $\mathrm{mg}$ to $1.5 \mathrm{mg} / \mathrm{kg} / \mathrm{day}$ ), alone or in combination with immunosuppressive agents is the main treatment option; however, they usually require lesser doses and shorter duration of GC use..$^{2,16}$

Another use of topical steroids is for oral lesions in pemphigus vulgaris (PV). Instead of increasing the systemic GCs dosage, the use of local GCs (triamcinolone gel, inhaler GCs, GC mouthwash and intralesional injections) might be helpful for these slowly responding oral erosions with or without systemic GCs. ${ }^{2}$ GC mouthwashes (Dexamethasone mouthwashes; $5 \mathrm{~mL}$ of 100g/ $\mathrm{mL}$ ) is helpful with a 5-minute swish-and-spit regimen 
used two to four times per day for oral lesions and erosions. Adherence of medication to the mucosa can be enhanced by drying the mucosa with soft tissue paper before each application, and having one application directly before bed, as oral secretions are reduced during sleep. ${ }^{15}$

GCs sprays and inhalers can be used especially for nasal, pharyngeal and oesophageal disease. Topical GCs might also be used in order to control the ocular disease and should be initiated in consultation with an ophthalmologist $^{17}$ Intralesional GCs injections are also useful for recalcitrant lesions of mucosa (ocular or oropharyngeal), applied every 2-4 weeks. However, its use is limited because of its side effects, such as cataract formation ${ }^{15}$ (Table 1). Side effects due to topical steroids for oral lesions are less common.

\section{Systemic therapy}

GCs can be used in either high, medium or lower doses. GCs at a prednisone-equivalent dose of less than $10 \mathrm{mg}$ /day are considered low dose GC therapy. This is based on a review by Da Silva JA et al. which showed decreased rates of osteoporosis, myopathy, cardiovascular disease, and glaucoma below this dose. ${ }^{18}$ They are also used either short-term (less than 3 weeks) or long-term. In short-term treatments gradual dose reduction is not necessary. ${ }^{14}$ For long-term GC treatment, gradual dose reduction is important for adrenal recovery. In order to prevent adrenal insufficiency and prevent relapses of AIBD, the dose of GCs is advised to be reduced progressively by $25 \%$ at every two weeks when the disease is under control. If these symptoms occur, physician should return to the previous dose and reduce the dose more slowly. When $20 \mathrm{mg} /$ daily dose is reached, slower reduction by $2.5 \mathrm{mg}$ every 3-4 weeks is beneficial to prevent flares. $^{14}$

In order to reduce the GC toxicity, taking the GC early in the morning is important to maintain the hormone balance in the body as physiological cortisol levels are highest in the morning ${ }^{14}$ (Table 1). Bone protection with vitamin D and several treatment options is important in anyone starting GCs more than $5 \mathrm{mg}$ /day for more than
3 months or who is already at risk of fracture or known osteopenia at less duration. ${ }^{1,19}$

\section{Glucocorticoid toxicity index (GTI)}

Recently, 19 experts with significant experience in the clinical use and pharmacology of GCs representing different specialties (like rheumatology, ophthalmology, dermatology, neurology, infectious disease, psychiatry, etc.), have evaluated GC use and established a Glucocorticoid Toxicity Index (GTI). ${ }^{20}$ GTI aims to measure the side effects due to GC therapy and their degree of deterioration over time from the initial start of GC. They established two forms of GTI; Composite GTI (9 domains/ 31 items totally) and Specific List (11 domains/ 23 items in total). The components of Composite GTI and Specific List can be further examined by the publication of Miloslavsky et al. ${ }^{20}$ Composite GTI are composed of common side effects that clearly related to GC use and differentiates between patients with high and low GC use. They demonstrate any deterioration due to GC exposure or improvement within 6 months to 3 years. The Specific List includes serious GC-related adverse events which are uncommon; however, have little potential for improvement showing mainly irreversible toxicity due to GC. ${ }^{20}$ Their first evaluation of the Composite GTI demonstrated excellent reliability and validity. ${ }^{20}$

The GTI is established for all disciplines. They suggested it be used at 3-monthly intervals apart from BMD measurements, which are supposed to take place not more than once a year during the GC therapy, using the initial assessment as the baseline. Recently, Ehler et al. studied this index in a prospective cohort of GC-treated vasculitis patients. ${ }^{21}$ Furthermore, currently, researchers supervised by DFM are investigating the GTI in their patients with AIBD retrospectively and prospectively. This might be helpful for measuring the toxicity of GC in AIBD as well as assessing the clinical effects of steroid-sparing agents in a more organized manner with reliable outcome measures.

\section{Body mass index (BMI)}

Weight gain and Cushingoid appearance are common clinical findings among patients with GC therapy. In- 
Table 1. Adverse effects associated with glucocorticosteroid use. ${ }^{1,7,15,18,20,23}$

Local (cutaneous)

\section{Systemic}

Metabolic

Wight gain, Obesity

Hyperglycaemia and diabetes mellitus

Negative nitrogen balance

Sodium retention, Odem

Secondary adrenal insufficiency

Diabetic ketoacidosis

Diabetic retinopathy-nephropathy-neuropathy Suppression

of growth in children

Cardiovascular

Hypertension

Hyperlipoproteinemia, development of early atherosclerosis Cardiovascular diseases (MI, stroke)

Congestive heart failure (with cardiac dysfunction)

Deep venous thrombosis

Pulmonary embolism

\section{Bone and musculoskeletal}

Skin

Atrophy

Striae

Acne

Easy injury (ecchymosis, petechiae, purpura)

Telangiectasia

Hypertrichosis

Hypo- or hyperpigmentation

Impairment of wound healing

Secondary fungal and microbial infections

Allergic contact dermatitis

\section{Mucosa}

Atrophy

Candidiasis

Dyspepsia

Impairment of wound healing

Secondary fungal and microbial infections
Myopathy

Joint pain with reduced dose

Osteoporosis

Osteopathy (Insufficiency fractures or aseptic osteonecrosis)

Tendon rupture

Skin

Acne

Striae

Easy injury (ecchymosis, petechiae, purpura)

Telangiectasia

Impairment of wound healing

Secondary microbial infections

Infections

Increased risk of infections of all bacterial, viral, mycobacterial, fungal, protozoal (especially long-term high dose therapy)

Severe infection (e.g. pneumonia and septicaemia)

Neuropsychiatric toxicity

Benin intracranial hypertension, or pseudotumor cerebri

Mental changes, depression, insomnia, ofori, appetite increa-

se

Psychosis

GCD-induced violence

\section{Gastrointestinal}

Peptic ulcer (mainly gastric)

Hepatomegaly and fatty liver

GI perforation and bleeding

Diverticulitis, cholecystitis

Pancreatitis

"Silent" bowel perforation

Ophthalmologic

Posterior subcapsular cataract

Glaucoma, increased intraocular pressure

Exophthalmos

Central serous retinopathy

Hematologic / immunological

Neutrophilia, monocytopenia, lymphopenia

Suppressed late type hypersensitivity

Infection 
creased appetite associated with GCs and increased food intake for symptomatic relief in patients with gastropathy or peptic ulcer disease are the common reasons for weight gain. ${ }^{22}$ Cushingoid features are truncal obesity, buffalo hump, and moon face due to the redistribution of body fat as a result of long-term glucocorticoid therapy. BMI is an accepted parameter to assess weight gain and its normal range is $18.5-24.9 \mathrm{~kg} / \mathrm{m}^{2}$. A major increase in $\mathrm{BMI}$ is defined as an increase by 5 to $8 \mathrm{BMI}$ units above normal BMI $\left(24.9 \mathrm{~kg} / \mathrm{m}^{2}\right) .{ }^{20}$ If there is a major increase, it is important because increased BMI is usually accompanied with hypertension, hyperlipidaemia, glucose intolerance and cardiovascular risks. ${ }^{22}$ During GC therapy, patients should be examined for BMI and any change should be noted and suggestions for balanced diet and regular exercises should be given at follow-up visits.

\section{Glucose tolerance}

GCs increase blood sugar. It is especially important as this makes controlling the existing diabetes even more difficult. Long-term GC use in diabetic patients might increase the development of serious organ damage due to diabetes like retinopathy, nephropathy and neuropathy. ${ }^{23}$ Initiating new diabetes by GC therapy is rare and it only occurs at very high doses. In terms of glucose tolerance; blood sugar, HgbAlc and diabetic medications (number and dose) should be noted and evaluated for any change. In most patients, a few months after cessation of corticosteroid, the blood sugar level returns to the pre-treatment state. ${ }^{7,20}$

\section{Blood pressure (BP)}

Hypertension is a common side effect which is more common in patients with underlying hypertension, kidney disease or in elderly population. Pregnant women receiving GC therapy have a slightly increased tendency to develop glucose intolerance. GC therapy starts to increase blood pressure after the first 2 weeks. Thus, short term therapies do not cause hypertension. ${ }^{22,23}$

Hypertensive emergencies are hypertensive crises characterized by acute, severe elevations in blood pressure, typically greater than 200/120 mmHg. They might be associated with or without target-organ dysfunction.
Some of the specific target-organ dysfunctions associated with hypertensive urgencies are; cerebral infarction, hypertensive encephalopathy, acute pulmonary oedema, acute congestive failure, acute coronary ischemia, acute kidney injury/failure, retinal haemorrhage/exudate, eclampsia and aortic dissection. This syndrome needs urgent intervention and treatment. ${ }^{24}$

Intermittent evaluation of BP (systolic and diastolic BP) is necessary in order to document any changes due to GC therapy. Furthermore, any decrease or increase of BP medications (number or dosage) should be examined during the follow-up visits. The salt and water retention effects of GCs also increase the blood pressure. Salt-free diet should be suggested to avoid this effect.

\section{Lipids}

GCs raise blood fats, usually by increasing triglycerides the most, but also there might be an increase in LDL. In those patients with risk, a poor diet of fats (especially saturated fat) should be recommended. ${ }^{22,23}$ In order to check lipid metabolism in patients with long-term use of GC, especially concentration of LDL and any changes in medications for hyperlipidaemia should be noted and followed.

\section{Musculoskeletal side effects}

\section{Steroid myopathy}

Symmetrical weakness of the proximal muscles without any other apparent cause is the main symptom of GC-associated myopathy. Typically, it is seen with a dose greater than $40 \mathrm{mg}$ / day prednisone equivalent GC. Muscle strength (evaluated according to the standards of Medical Research Council strength testing scale), necessary laboratory work (like muscle enzymes, electromyelography, etc.), functional limitations in daily routine (difficulty to rise from a chair, to climb up the stairs, etc.) should be asked and examined at beginning of GC therapy and further in the follow-up visits. ${ }^{22,25}$ Regular exercises and enough protein intake are recommended along with decreasing GC dose or switching it to an overnight treatment regimen. 


\section{Bone mineral density}

Osteoporosis is one of the most common side effects in patients with long-term GC treatment. Bone demineralization is at highest rate in the first 6-12 months of GC therapy and highest bone loss is usually observed in young males with high bone mass. ${ }^{1}$ Osteoporosis usually results in bone pain, fractures and vertebral collapse. Axial skeleton with trabecular bones (vertebra, ribs) has eight times higher metabolic cycle and thus, higher demineralization rate than cortical bone areas (long bones). Vertebral collapse fractures are detected on routine radiograms of $\mathrm{X}$-ray examinations of axial skeleton. Dual-energy X-ray absorptiometry of mineral density (DEXA) is the best evaluation text with high sensitivity, repeatability and low radiation exposure rate for osteoporosis. ${ }^{1} \mathrm{~T}$ score in the densitometry report shows that average values in the healthy control population is used to express a standard deviation. Osteopenia is defined as a $\mathrm{T}$ score below the average -1 to -2.5 . If the $\mathrm{T}$ score is below -2.5 , this defines osteoporosis. 22,26

Bone Mineral Density (BMD) should be evaluated before GC treatment and repeated in every 12 months during GC therapy. Any changes in BMD and medications for osteopenia or osteoporosis should be documented at every visit. It is advised to suggest patients using GC therapy to quit smoking, to restrict alcohol and caffeine consumption, to do regular exercises, to eat foods containing high amounts of calcium (skimmed milk and dairy products), to avoid trauma, to consult with doctors to use calcium vitamin D supplements ( 1.5 grams $\mathrm{Ca} / 800 \mathrm{IU} \mathrm{D}$ vit daily) as well as drugs to prevent bone resorption (like bisphosphonates). ${ }^{19,22}$ Insufficiency fractures (IFs) are a subtype of stress fractures, commonly associated with osteoporosis and Vitamin D deficiency as well as GC use. ${ }^{27}$

\section{Avascular necrosis}

It is an uncommon; however, serious adverse effect of GC therapy. Usually the initial symptom is localized pain during activity, which then starts to arise even at rest. The proximal femur is the most common site. It is often seen between 6 tol 2 months of the treatment. The most specific and sensitive method to confirm the diagnosis is magnetic resonance imaging (MRI) as standard $\mathrm{X}$-ray imaging is not always helpful for osteonecrosis. Main approach is to rest, prevention from trauma and using cane as well as ceasing the GC treatment. In advanced cases, surgical approaches are needed. ${ }^{28}$

\section{Skin toxicity}

GCs affect keratinocytes and prevent secretion of collagen and hyaluronic acid by fibroblasts in dermis resulting in cutaneous adverse effects. The most common side effects due to GCs are; acneiform rash, easy bruising, hirsutism, atrophy, striae, erosions, tears and ulcerations, included in the composite GTI. Apart from atrophy and stria, these side effects are prone to disappear after discontinuation of GCs. ${ }^{18,22}$

\section{Infections}

Patients with long-term GCs use have an increased susceptibility to infections. Opportunistic infections (oral or vaginal candidiasis or zoster infections or cutaneous staphylococcal infections) are the most common and first-developed ones. However, serious infections which need intravenous antibiotic, antifungal, or antiviral intervention or even life-threating infections need hospitalization and urgent intervention can be seen during GC therapy, fortunately less common. ${ }^{20,22}$

Early diagnosis of infections may be difficult because fever and inflammation symptoms are concealed by the effect of GCs. Physicians should check for signs of infection during the follow-up period. Another important point for patients before undergoing long-term GC therapy is vaccination status. Live virus vaccines should not be given to adults during GC therapy and within one month of cessation of GCs as antibody response to vaccination is insufficient in these patients. ${ }^{7}$

\section{Endocrine side effects (SE)}

Growth retardation is an uncommon; however, severe adverse effect of GCs. When GCs are given before 2 years of age or in puberty, changing degrees of growth retardation might be a problem. Other than these periods, normal growth usually continues with the dis- 
continuation of GC treatment. Patients should be monitored for growth and normal development of puberty at every 3-6 months during follow-up visits. If necessary, growth hormone therapy should be given. ${ }^{23}$

GCs are so similar to cortisol; thus, prolonged use of high dose GCs can cause the adrenal glands to stop making cortisol. This usually causes adrenal suppression. Adrenal insufficiency is characterized by arthralgia, myalgias, weakness, headache, mood changes, gastrointestinal symptoms (eg nausea, vomiting, anorexia) and rarely low blood pressure and shock. This syndrome is usually seen by abrupt cessation of GCs. ${ }^{22}$ In these cases, morning blood cortisol levels should be measured and consulted by an endocrinologist in order to manage the appropriate treatment regime.

\section{Gastrointestinal (GIS) SE}

GC therapy has common GIS side effects such as nausea, vomiting, gastroesophageal reflux, peptic ulcers, fungal infection of the oesophagus, fatty liver and fatty inflammation of the pancreas in people with high triglycerides and in some GIS perforation and haemorrhage. ${ }^{29,30}$ Concurrent nonsteroidal anti-inflammatory drug use, advanced age, history of peptic ulcer, anticoagulant treatment, smoking and the use of alcohol are other risk factors increasing the chance of GIS side effects. GCs usually cause gastric ulcers rather than duodenal localization. The use of $\mathrm{H}_{2}$ receptor antagonists or proton pump inhibitors can reduce the risk of these adverse effects. ${ }^{23}$ To reduce the side effects on the stomach, GCs should also be taken with food or after meals.

\section{Ocular SE}

The most common side effects of GCs in the eye are cataract and intraocular pressure elevation (glaucoma). ${ }^{31}$ Children seem to be more prone to cataracts than adults even with lower doses and in shorter periods although personal predisposition is also important. ${ }^{7}$ Posterior subcapsular cataract is the most specific form of adverse effect in eye due to GCs. The most important factors in its occurrence are duration of treatment and cumulative GCs dose. Other ocular side effects due to GCs include ptosis, mydriasis, opportunistic infections such as her- petic keratitis and central serous retinopathy. ${ }^{32}$ An eye examination every 6-12 months during corticosteroid treatment is necessary.

\section{Neuropsychiatric toxicity}

The main manifestations of GC-neurotoxicity are insomnia, emotional lability, mood changes like mania and depression, GC-induced violence, cognitive impairment, psychosis and other severe neuropsychiatric symptoms (persecutory delusions or auditory hallucinations). 1,33 "Steroid psychosis" is the most severe form of adverse psychological side effect of GCs, occurring in $5 \%$ to $6 \%$ of adult patients. ${ }^{34}$ These psychological changes are usually seen within a few days of treatment, they might vary in duration and disappear when the GCs dose is decreased or stopped.. 35,36

\section{Posterior reversible encephalopathy syndrome}

Posterior reversible encephalopathy syndrome (PRES) is a cerebrovascular syndrome typically with reversible vasogenic oedema. It is characterized by acute neurological symptoms including headache, confusion, vision changes, seizures, and focal neurological deficits. PRES usually occurs after hypertension due to problematic cerebrovascular autoregulation..$^{37-39}$

\section{Obstetrics}

GCs pass into breast milk. However, breastfeeding is not forbidden if breastfeeding times are arranged and done about 4 hours after GC intake according to the American Academy of Paediatrics. ${ }^{40}$ GC therapy may also cause amenorrhea in non-pregnant women, especially when it is used as IM injections. Women should be informed about these issues. ${ }^{7}$

\section{Conclusion}

Developing novel therapies for AIBD is based on increased understanding of the specific mechanisms and pathogenesis involved in the development of the disease. These new therapies will need to show both efficacy and safety preferably more than GCs and current medications. Thus, using reliable outcomes is essential 
to determine the efficacy and safety of new drugs and to allow comparing the overall toxicity and safety. GTI might be an enormous help in that process.

\section{Acknowledgements}

This research did not receive any specific grant from funding agencies in the public, commercial, or not-forprofit sectors.

\section{References}

1. Frew JW, Murrell DF. Corticosteroid use in autoimmune blistering diseases. Immunol Allergy Clin North Am 2012;32:283-94.

2. Hertl M, Jedlickova H, Karpati S, et al. Pemphigus. S2 Guideline for diagnosis and treatment--guided by the European Dermatology Forum (EDF) in cooperation with the European Academy of Dermatology and Venereology (EADV). J Eur Acad Dermatol Venereol 2015;29:405-14.

3. Joly P, Maho-Vaillant M, Prost-Squarcioni C, et al. First-line rituximab combined with short-term prednisone versus prednisone alone for the treatment of pemphigus (Ritux 3): a prospective, multicentre, parallel-group, open-label randomised trial. Lancet 2017;389:2031-40.

4. Murrell DF, Peña S, Joly P, et al. Diagnosis and Management of Pemphigus: recommendations by an International Panel of Experts.J Am Acad Dermatol. 2018 Feb 10. pii: S0190-9622(18)30207-X. doi: 10.1016/j.jaad.2018.02.021. [Epub ahead of print].

5. Bilgic Temel A, Murrell DF. Pharmacological advances in pemphigus. Curr Opin Pharmacol 2019;46:44-9.

6. McDonough AK, Curtis JR, Saag KG. The epidemiology of glucocorticoid-associated adverse events. Curr Opin Rheumatol 2008;20:131-7.

7. Otoimmün Büllöz Hastalıklar Kitabı. Ed. Soner Uzun. Bölüm 5: Otoimmün büllöz hastalıkların tedavisinde kullanılan yöntemler ve öneriler. Uzun S, Eskocak AH. 2a: Sistemik Kortikosteroidler 2017:175-86.

8. Burns CM. The history of cortisone discovery and development. Rheum Dis Clin North Am 2016;42:114.

9. Sulzberger MB, Witten VH, Kopf AW. The topical and systemic use of corticosteroids in the treatment of skin disease. Postgrad Med 1958;24:379-92.

10. Nesbitt LT. Glucocorticokortikosteroids. In: Bolognia JL, Jorizzo JL, Rapini RP, editors. Dermatology. 2nd ed. Spain: Mosby Elsevier; 2008. p. 125.

11. Otoimmün Büllöz Hastalıklar Kitabı. Ed. Soner
Uzun. Bölüm 5: Otoimmün Büllöz Hastalıkların Tedavisinde Kullanılan Yöntemler ve Öneriler. Uzun S, Bilgiç Temel A. 5-2a: Otoimmün Büllöz Hastalıklarda Yerel Tedavi (5-1a) 2017:161-7.

12. http://www.bad.org.uk/shared/get-file.ashx?id=3427 \&itemtype=document)

13. Mooney E, Rademaker M, Dailey R, et al. Adverse effects of topical corticosteroids in paediatric eczema: Australasian consensus statement.Australas J Dermatol 2015;56:241-51.

14. Uzun S. Pemfigusun Güncel Tedavisi ve Yönetimi. Turk J Dermatol 2012;6:91-101.

15. Jain SV, Murrell DF. Topical corticosteroids in blistering diseases in: A treatise on topical corticosteroids in dermatology use, misuse and abuse. Ed: Lahiri K. Singapore: Springer Nature Singapore Pte Ltd; 2018 P. 91-100.

16. Feliciani C, Joly P, Jonkman MF, et al. Management of bullous pemphigoid: the European Dermatology Forum consensus in collaboration with the European Academy of Dermatology and Venereology. Br J Dermatol 2015;172:867-77.

17. Fleming TE, Korman NJ. Cicatricial pemphigoid. J Am Acad Dermatol 2000;43:571-94.

18. Da Silva JA, Jacobs JW, Kirwan JR, et al. Safety of low dose glucocorticoid treatment in rheumatoid arthritis: published evidence and prospective trial data. Ann Rheum Dis 2006;65:285-93.

19. American College of Rheumatology Ad Hoc Committee on Glucocorticoid-Induced Osteoporosis recommendations for the prevention and treatment of glucocorticoid induced osteoporosis. Arthritis Rheum 2001;44:1496-503.

20. Miloslavsky EM, Naden RP, Bijlsma JW, et al. Development of a glucocorticoid toxicity index (GTI) using multicriteria decision analysis. Ann Rheum Dis 2017;76:543-6.

21. Ehlers L, Wiebe E, Freier D, et al. Prospective use of the glucocorticoid toxicity index (GTI) in a cohort of vasculitis patients. Ann Rheum Dis: first published as 10.1136/annrheumdis-2019-eular.876 on 27 June 2019. http://ard.bmj.com/)

22. Oray M, Abu Samra K, Ebrahimiadib N, Meese H, Foster CS. Long-term side effects of glucocorticoids. Expert Opin Drug Saf 2016;15:457-65.

23. Jackson SM, Nesbitt LT. Glucocorticosteroids. In: Bolognia JL, Jorizzo JL, Schaffer JV, editors. 3rd ed. New York: Elsevier Saunders 2012. p. 2075-88.

24. Ram CV, Silverstein RL. Treatment of hypertensive urgencies and emergencies. Curr Hypertens Rep 2009;11:307-14.

25. Gupta A, Gupta Y. Glucocorticoid-induced myopathy: Pathophysiology, diagnosis, and treatment. Indian J Endocrinol Metab 2013;17:913-6. 
26. Grossman JM, Gordon R, Ranganath VK, et al. American College of Rheumatology 2010 recommendations for the prevention and treatment of glucocorticoid-induced osteoporosis. Arthritis Care Res 2010;62:1515-26.

27. Vaishya R, Agarwal AK, Banka PK, Vijay V, Vaish A. Insufficiency fractures at unusual sites: A Case Series. J Orthop Case Rep 2017;7:76-9.

28. Weinstein RS. Glucocorticoid-induced osteonecrosis. Endocrine 2012;41:183-90.

29. Luo JC, Chang FY, Lin HY, et al. The potential risk factors leading to peptic ulcer formation in autoimmune disease patients receiving corticosteroid treatment. Aliment Pharmacol Ther 2002;16:1241-8.

30. Narum S, Westergren T, Klemp M. Corticosteroids and risk of gastrointestinal bleeding: a systematic review and metaanalysis. BMJ Open 2014;4:e004587

31. Fel A, Aslangul E, Le Jeunne C. Eye and corticosteroid's use. Presse Med 2012;41:414-21.

32. Miller D, Peczon JD, Whitworth CG. Corticosteroids and functions in the anterior segment of the eye. Am J Ophthalmol 1965;59:31-4.

33. Munjampalli SK, Davis DE. Medicinal-induced behavior disorders. Neurol Clin 2016;34:133-69.

34. Satel SL. Mental status changes in children receiving glucocorticoids: review of the literature. Clin Pediatr 1990;29:382-8.

35. Ling MHM, Perry PJ, Tsuang MT. Side effects of corticosteroid therapy: psychiatric aspects. Arch Gen Psychiatry 1981;38:471-7.

36. Lewis DA, Smith RE. Steroid-induced psychiatric syndromes. J Affect Disord 1983;5:319-32.

37. Parikh NS, Schweitzer AD, Young RJ, et al. Corticosteroid therapy and severity of vasogenic edema in posterior reversible encephalopathy syndrome. J Neurol Sci 2017;380:11-5.

38. Fugate JE, Rabinstein AA. Posterior reversible encephalopathy syndrome: clinical and radiological manifestations, pathophysiology, and outstanding questions. Lancet Neurol 2015;14:914-25.

39. Liman TG, Bohner G, Heuschmann PU, Endres M, Siebert E. The clinical and radiological spectrum of posterior reversible encephalopathy syndrome: the retrospective Berlin PRES study. J Neurol 2012;259:155-64.

40. No authors listed. American Academy of Pediatrics Committee on Drugs: The transfer of drugs and other chemicals into human milk. Pediatrics 1994;93:137-50. 